\title{
Quantifying the global solar radiation received in Pietermaritzburg, KwaZulu-Natal to motivate the consumption of solar technologies
}

https://doi.org/10.1515/phys-2018-0098

Received Apr 16, 2018; accepted Aug 13, 2018

\begin{abstract}
In South Africa, power outages and scheduled load shedding are common practices in a bid to safeguard power resources. With the increase in cost of conventional energy sources, and the depletion of fossil fuels, attempts to use renewable resources to their full potential are underway. South Africa and in particular Pietermaritzburg receives sunshine throughout the year, making it suitable for harnessing solar power. In this work we estimate the amount of Global Solar Radiation (GSR) received in Pietermaritzburg which is the capital of the KwaZulu-Natal province. An air temperature model (Hargreaves-Samani) is used to approximate the GSR received in Bisley in comparison to measured data obtained from the ARC, for a period of one calendar year (July 2014 - June 2015). We proceed to apply the Angstrom-Prescott model to evaluate the competence of the initial prediction method. The primary aim of this study is to validate the efficiency and accuracy of the above-mentioned forecasting models, for areas within close proximity. Our results compare fairly well with the observed data provided by the ARC. Both models prove to sufficiently estimate the amount of GSR incident in Bisley. The deviations from the actual measured values suggest that a model which incorporates both variables may improve the accuracy of GSR estimations. The use of comprehensive prediction and forecasting models will allow for optimal placement of solar technologies for the harnessing of GSR within Pietermaritzburg. Though Pietermaritzburg may not be suitable for large scale solar power plants, the employment of solar panels in both in-
\end{abstract}

\footnotetext{
${ }^{\star}$ Corresponding Author: Naven Chetty: University of KwaZuluNatal, School of Chemistry and Physics, Private Bag X01, Scottsville 3209, Pietermaritzburg, South Africa

Email: chettyn3@ukzn.ac.za

Tamara Rosemary Govindasamy: University of KwaZulu-Natal, School of Chemistry and Physics, Private Bag X01, Scottsville 3209, Pietermaritzburg, South Africa
}

dustrial and residential areas will contribute greatly to a decrease in demand of grid electricity.

Keywords: Load shedding, global solar radiation, photovoltaic technologies, air temperature model, AngstromPrescott model

PACS: 88.40.fc, 88.40.ff, 92.60.Vb, 92.60.Aa

\section{Introduction}

Solar energy is a pure, inexhaustible, and readily available resource. The escalation in price of conventional energy sources, together with the depletion of non-renewable resources and fossil fuels, necessitates a great demand for alternative power sources. Green energy sources which are beneficial to the environment are being studied as alternate resources which could potentially assist in the energy crisis. The cost of these technologies has reduced significantly in the past decade, however it still remains higher than the cost of conventional energy and hence uptake is still relatively slow [1].

Within South Africa, we rely solely on the energy harnessed from coal power stations operated by ESKOM, the state power utility. The increased demand for electricity has resulted in a rise in production costs due to the strain placed on existing power stations, aging infrastructure as well as the depletion of non-renewable resources [2]. Since our country has been alarmed about the security of energy resources for the country's energy demands, load shedding (power outages) have been implemented almost daily over the past few years in an attempt to save energy [2]. The consequences of load shedding have affected the entire country with even more devastating effects on the economy [2,3]. Though resources have recently been secured to increase energy production, the cause of the crisis cannot be cured. The depletion of non-renewable energy sources remains an issue, and will surely result in greater consequences in the long-term. 
Growth in solar energy technologies has been noted, together with its theoretical potential to supply the global demand for energy being the major contributing factor [1]. South Africa is well suited for the harnessing of solar radiation because sunshine is available throughout the year including the winter months. Depending on the geographical location certain areas in Africa receive more than double the amount of radiation as compared to countries in the northern hemisphere [3]. Despite this abundance, there are many financial and technical restraints with regards to solar energy technologies, which limit its use to private off-grid connections. These limitations need to be overcome in order to increase the contribution of solar power to the energy supply of the country.

The amount of solar radiation incident at the earth's surface is a measurable quantity. Solar radiation outside of the earth's atmosphere, received at a surface which is normal to the incident radiation is known as the solar constant $[4,5]$. This quantity is measured from space through the use of satellite data and has a value of $1367 \mathrm{Wm}^{-2}$, which changes by approximately $0.01 \%$ over a period of 30 years [5-8]. The amount of solar radiation received at the earth's surface is largely depleted due to the attenuation processes which occur in the atmosphere [6].

Solar radiation is responsible for many processes which transpire on the earth's surface and its research finds applications in many science and engineering fields [9]. Knowledge and prediction of solar radiation available at a specific location is of great importance for the designing and performance evaluation of solar energy conversion systems $[9,10]$. Solar energy can be harnessed and utilized for applications which fall into two main categories; Solar Thermal and Solar Photovoltaic (PV) $[1,9,10]$.

In many geographical locations, Global Solar Radiation (GSR) is not measured because it is too expensive to purchase and maintain the apparatus required. If measured data is available, it is not always complete as equipment can fail due to numerous faults $[9,11]$. As a result, accurate and efficient forecasting methods are increasingly required. Hence, researchers have employed the use of empirical methods which are able to calculate and predict GSR for a particular location [5, 9, 11-13].

Many of these empirical models require the input of other meteorological variables (which are often more accessible than solar radiation data) or historical weather data. Some of these meteorological parameters include; air temperature, precipitation, relative humidity, sunshine duration, etc. [11-13]. The empirical model is classified according to the climatic variable which it requires [9], e.g. sunshine duration models [10,13-16], temperature based methods [9, 17-19], and cloud-based methods which require the use of satellite sky images [6].

Although industries within South Africa are aware of the solar technologies which exist, they are not being implemented to translate their true potential. With accurate prediction and forecasting models for our country, we may be able to enhance the use of these technologies while alleviating the strain placed on existing energy infrastructure.

\section{Sample site details}

The city of Pietermaritzburg (Midlands) is the capital city of the KwaZulu-Natal province in South Africa. This city is found in a hollow which is surrounded by the escarpment (Drakensberg Mountain Range) and is seen as an inland region. Having a geographical location that ideally receives sunshine throughout the year, Pietermaritzburg is one of the warmest cities in the province. Weather stations in the neighboring cities were unable to provide records of daily solar radiation or sunshine duration for Pietermaritzburg. Such data is not readily available for this location, hence making this work significant as a predictor of GSR. A study center in Ukulinga (Bisley, Pietermaritzburg), was able to provide the necessary data required for this work. Temperature, Humidity and Dew point measurements were recorded hourly with the use of a sensor. Table 1 provides the geographical data of the site considered in this study. The land use in Bisley has more of an industrial and commercial setting. Figure 1 is a satellite illustration of Bisley, Pietermaritzburg.

Table 1: Geographical details of study sites

\begin{tabular}{lcc}
\hline & Bisley & Ukulinga \\
\hline Latitude $\Phi$ (South) & $-29.668^{\circ}$ & $-29.663^{\circ}$ \\
Longitude (East) & $30.416^{\circ}$ & $30.405^{\circ}$ \\
Elevation & $752 \mathrm{~m}$ & $750 \mathrm{~m}$ \\
\hline
\end{tabular}

The main focus of our research was to estimate the amount of GSR received in Pietermaritzburg using meteorological data which is readily and easily available. Since the cost of equipment to measure certain climatic parameters was too high, we decided to use an approach that estimated solar radiation using air temperature and sunshine duration. Records of solar radiation incident in Pietermaritzburg are conducted by the Agricultural Research Council (ARC). The ARC conducts work with the Ukulinga Research Center (based in Bisley), and was able to provide 


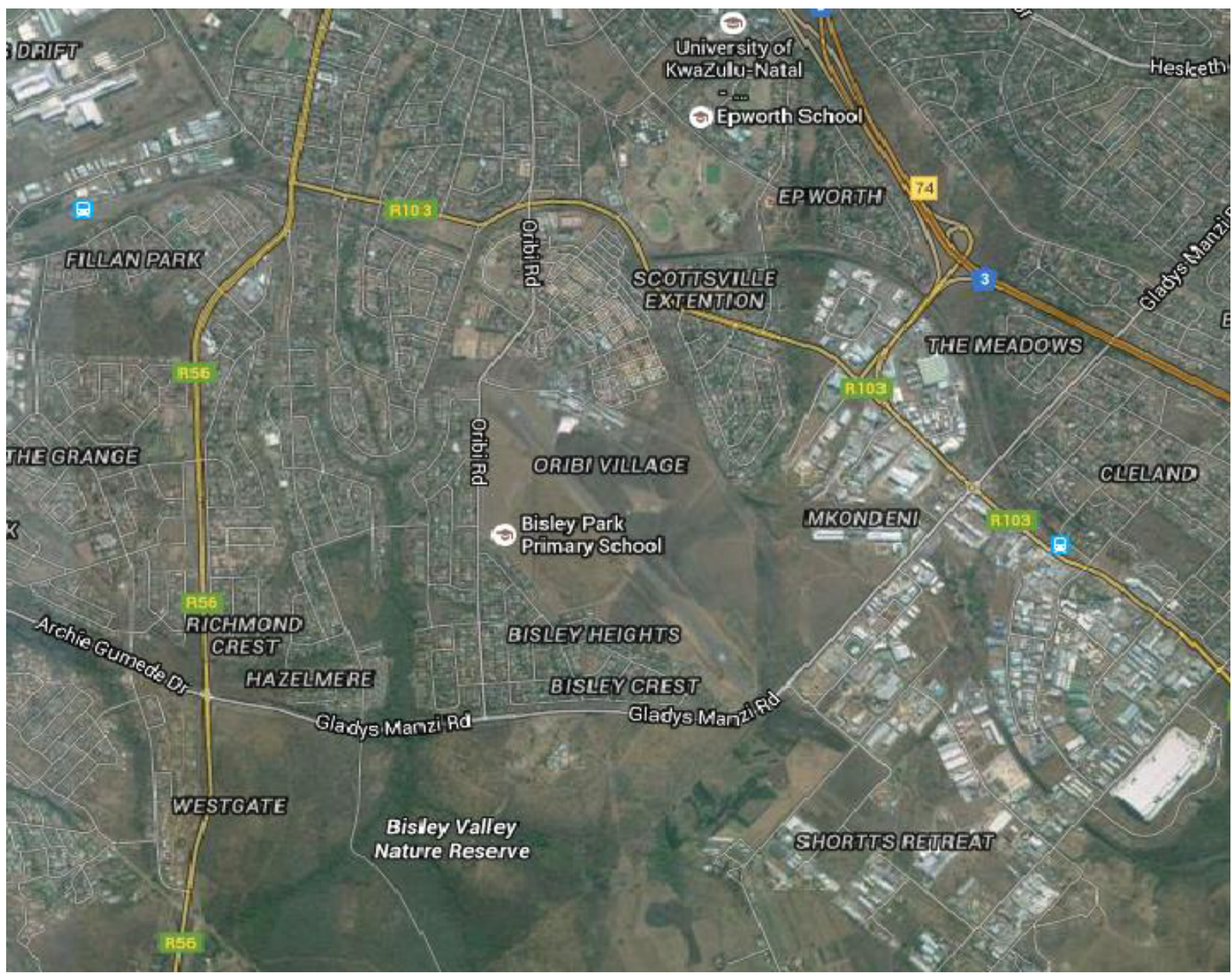

Figure 1: Satellite image of Scottsville, Bisley [Google maps]

the necessary GSR data for this study. This data was used to verify our calculations and interpret our differences. The Hargreaves-Samani equation [19] was applied to calculate the solar radiation incident on a horizontal surface, for Bisley following the approach studied by Maluta et al. [20]. Thereafter we proceeded to validate this method using the Angstrom-Prescott model. Due to time and equipment constraints we were only able to yield measurements over a period of one calendar year, however this technique can be further developed to analyze historic data for any location.

\section{Background theory}

In areas where solar radiation information is inaccessible, methods of forecasting are employed. The simplest method involves the use of the air temperature of a given location. Air temperature measurements are easy to con- duct and can be obtained in regions where there are no weather stations nearby. The Hargreaves-Samani equation [18-20] relates the amount of extraterrestrial radiation $\left(\mathrm{H}_{o}\right)$ to the difference between the maximum and minimum air temperatures $\left(\Delta T=\mathrm{T}_{\max }-\mathrm{T}_{\min }\right)$, in order to calculate the amount of GSR incident on a horizontal surface $(\mathrm{H})$, using the equation below $[6,11,17,18,20]$;

$$
H=H_{o} K_{r}(\Delta T)^{0.5}
$$

where the empirical coefficient $\mathrm{K}_{r}=0.16$ for 'interior regions' and $\mathrm{K}_{r}=0.19$ for 'coastal regions' [9, 17, 20]. The extraterrestrial radiation $\mathrm{H}_{o}$; is given by $[6,16,21,22]$;

$$
\begin{aligned}
H_{O} & =\frac{24 \times 3.6 \times 10^{-3} I_{s c}}{\pi}\left[1+0.033 \cos \left(\frac{2 \pi D_{n}}{365}\right)\right] \\
& \cdot\left[\cos \phi \cos \delta \sin \omega_{s}+\omega_{s} \sin \phi \sin \delta\right]
\end{aligned}
$$

where $I_{s c}=1367 \mathrm{~W} / \mathrm{m}^{2}$ is known as the solar constant [6, $16,20], D_{n}$ is the Julian calendar day of the year (Jan 1st corresponds to $\mathrm{D}_{n}=1$, Dec 31st corresponds to $\mathrm{D}_{n}=365$ ). 
The latitude of the site is denoted by $\phi$; and all angles are calculated in radians. $\delta$, is the declination angle which is given by $[6,10,16,21,22]$;

$$
\delta=23.45 \frac{\pi}{180} \sin \left[\frac{2 \pi\left(D_{n}+284\right)}{365}\right]
$$

The sunset hour angle, $\omega_{s}$, is given by $[6,20,22,23]$;

$$
\omega_{s}=\cos ^{-1}(-\tan \phi \tan \delta)
$$

By calculating the solar angles it is possible to predict the amount of solar irradiance received on a horizontal surface at a given location. The clearness index $\left(K_{T}\right)$ describes the atmosphere's transparency and is found by comparing the amount of GSR to the amount of extraterrestrial solar radiation as shown by $[6,20,21]$;

$$
K_{T}=\frac{H}{H_{o}}
$$

The Angstrom-Prescott equation can be used to calculate the clearness index from the relative sunshine duration, provided the Angstrom-Prescott coefficients for the area are known $[6,14,15,21]$;

$$
K_{T}=\frac{H}{H_{o}}=a+b\left(\frac{S}{S_{o}}\right)
$$

where $a, b$ are the Angstrom-Prescott coefficients, $\mathrm{S}$ is the actual hours of sunshine received, and $S_{o}$; is the maximum possible duration of sunshine for a given day calculated from $[15,16,21,23]$;

$$
S_{o}=\frac{2 \omega_{s}}{15}
$$

For areas where the Angstrom coefficients are unknown, it is prescribed to use $a=0.25$ and $b=0.50$ [23].

The temperature data for Bisley (Commercial/ Industrial area) was studied for the period July 2014 - June 2015. A MT668 Temperature and humidity data logger was used to record hourly maximum and minimum temperatures, relative humidity and dew point for this location. The Hargreaves-Samani equation was applied to calculate the GSR for Bisley which was then related to the measured values for Ukulinga, provided by ARC. The Angstrom-Prescott model was used to validate the Hagreaves-Samani model, using measured sunshine duration data for Bisley. Thereafter, the clearness index was determined using each of the above models. We again verified the efficiency of both models in comparison to the measured quantities.

\section{Results and discussion}

Daily average measurements of temperature, relative humidity and dew point were recorded using data loggers cal-

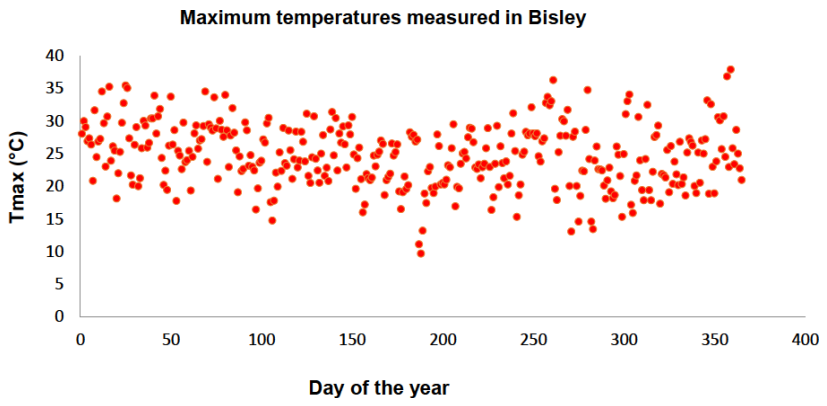

Figure 2: Graph of measured maximum temperatures for Bisley

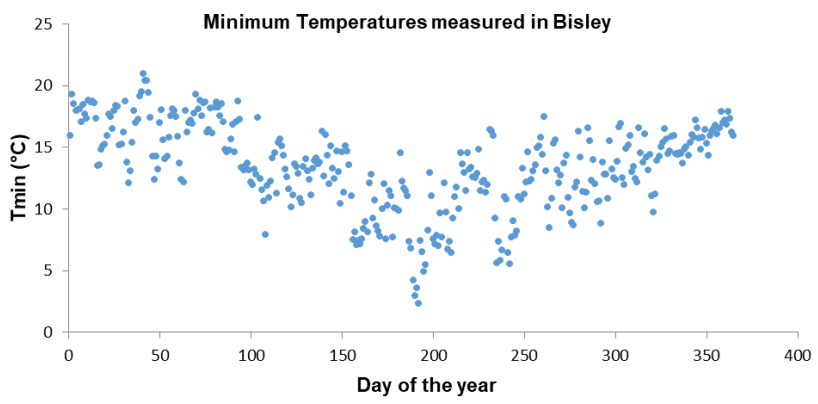

Figure 3: Graph of measured minimum temperatures for Bisley

ibrated in Bisley. Attention to their placement was essential as the sensors had to be installed at a height of $1,5 \mathrm{~m}$ above the ground and could not be sheltered, as this would alter the recordings drastically. Graphs showing the measured maximum and minimum air temperatures for this suburb are provided in Figures 2 and 3. These measurements were conducted for each day of the time period studied (July 2014 - June 2015). The latitude of Bisley was used to calculate the relevant solar angles using eqs. (3) and (4) which then allowed us to evaluate the extraterrestrial solar radiation (Ho) in Eq. (2). The Hargreaves-Samani (H-S) equation (Eq.(1)), together with the measured air temperature values gave results which are averaged in Table 2. The GSR values listed below are the calculated monthly averages based on daily maximum and minimum air temperatures. We then estimated the GSR for Bisley using measured sunshine duration hours and the Ho within the Angstrom-Prescott (A-P) model. The maximum possible sunshine duration Eq. (7) was calculated using the hour angle Eq. (4). These results are represented in Table 3.

The measured values $\left(\mathrm{H}_{\text {measured }}\right)$ listed in Tables 2 and 3, are the actual observed values of GSR for Bisley. The data was supplied by the ARC and enabled us to compare the values calculated by Eqs. (1) and (6) with the measured data. Temperature variations show a similar distribution to the $\mathrm{H}$ (both observed and calculated) values which illustrates the relationship between air temperature and GSR. 
Table 2: Bisley, Ukulinga results using the Hargreaves-Samani Model (July 2014-June 2015)

\begin{tabular}{ccccccc}
\hline Month & $\mathbf{T}_{\max }\left({ }^{\circ} \mathbf{C}\right)$ & $\mathbf{T}_{\min }\left({ }^{\circ} \mathbf{C}\right)$ & $\Delta \mathbf{T}\left({ }^{\circ} \mathbf{C}\right)$ & $\begin{array}{c}\mathbf{H}_{\mathbf{o}} \\
\left.(\mathbf{M}) / \mathbf{m}^{2} / \text { day }\right)\end{array}$ & $\begin{array}{c}\mathbf{H}_{\text {calculated }} \\
\left.(\mathbf{M}) / \mathbf{m}^{2} / \text { day }\right)\end{array}$ & $\begin{array}{c}\mathbf{H}_{\text {measured }} \\
\left(\mathbf{M J} / \mathbf{m}^{2} / \text { day }\right)\end{array}$ \\
\hline July & 21.84 & 8.10 & 13.74 & 19.98 & 11.69 & 12.34 \\
Aug & 23.73 & 11.34 & 12.38 & 24.70 & 13.70 & 13.71 \\
Sep & 27.37 & 12.54 & 14.82 & 31.34 & 18.98 & 17.88 \\
Oct & 22.51 & 12.56 & 9.95 & 37.63 & 18.48 & 15.34 \\
Nov & 22.60 & 14.14 & 8.47 & 41.95 & 19.03 & 14.94 \\
Dec & 26.01 & 15.96 & 10.05 & 43.74 & 21.61 & 17.63 \\
Jan & 27.46 & 17.10 & 10.36 & 42.94 & 21.64 & 19.69 \\
Feb & 26.23 & 16.55 & 9.68 & 39.69 & 19.50 & 19.45 \\
Mar & 27.08 & 16.76 & 10.32 & 34.13 & 17.32 & 17.83 \\
Apr & 23.86 & 13.51 & 10.35 & 27.31 & 13.75 & 14.58 \\
May & 25.84 & 12.99 & 12.84 & 21.58 & 12.25 & 13.76 \\
Jun & 22.11 & 9.80 & 12.32 & 18.87 & 10.47 & 12.44 \\
Average & $\mathbf{2 4 . 7 2}$ & $\mathbf{1 3 . 4 5}$ & $\mathbf{1 1 . 2 7}$ & $\mathbf{3 1 . 9 9}$ & $\mathbf{1 6 . 5 4}$ & $\mathbf{1 5 . 8 0}$ \\
\hline
\end{tabular}

Table 3: Bisley, Ukulinga results using the Angstrom-Prescott Model (July 2014-June 2015)

\begin{tabular}{ccccccc}
\hline Month & S (hours) & $\mathbf{S}_{\mathbf{o}}$ (hours) & $\mathbf{S} / \mathbf{S}_{\mathbf{o}}$ & $\begin{array}{c}\mathbf{H}_{\mathbf{o}} \\
\left(\mathbf{M} / \mathbf{m}^{2} / \text { day }\right)\end{array}$ & $\begin{array}{c}\mathbf{H}_{\text {calculated }} \\
\left(\mathbf{M J} / \mathbf{m}^{2} / \text { day }\right)\end{array}$ & $\begin{array}{c}\mathbf{H}_{\text {measured }} \\
\left(\mathbf{M} \mathbf{J} / \mathbf{m}^{2} / \text { day }\right)\end{array}$ \\
\hline July & 6.80 & 10.30 & 0.66 & 19.98 & 11.59 & 12.34 \\
Aug & 6.50 & 10.97 & 0.59 & 24.70 & 13.46 & 13.71 \\
Sep & 6.20 & 11.85 & 0.52 & 31.34 & 15.98 & 17.88 \\
Oct & 6.00 & 12.76 & 0.47 & 37.63 & 18.25 & 15.34 \\
Nov & 6.50 & 13.51 & 0.48 & 41.95 & 20.56 & 14.94 \\
Dec & 6.90 & 13.88 & 0.50 & 43.74 & 21.87 & 17.63 \\
Jan & 6.30 & 13.67 & 0.46 & 42.94 & 20.61 & 19.69 \\
Feb & 6.60 & 13.04 & 0.51 & 39.69 & 20.04 & 19.45 \\
Mar & 6.90 & 12.18 & 0.57 & 34.13 & 18.26 & 17.83 \\
Apr & 7.40 & 11.27 & 0.66 & 27.31 & 15.84 & 14.58 \\
May & 7.90 & 10.51 & 0.75 & 21.58 & 13.49 & 13.76 \\
Jun & 7.60 & 10.13 & 0.75 & 18.87 & 11.80 & 12.44 \\
Average & $\mathbf{6 . 8}$ & $\mathbf{1 2 . 0 1}$ & $\mathbf{0 . 5 8}$ & $\mathbf{3 1 . 9 9}$ & $\mathbf{1 6 . 8 1}$ & $\mathbf{1 5 . 8 0}$ \\
\hline
\end{tabular}

The accuracy of both models was determined based on the error analysis between the predicted and measured values of GSR. Table 4 provides the average annual errors for the Hargreaves-Samani (H-S) and Angstrom-Prescott (A-P) models. The mean bias error (MBE) indicates the average deviance of the calculated values from that of the measured and is used to decide the long-term performance of a model [24]. Positive values of MBE correspond to an over estimation, while a negative MBE indicates an under estimation. The RMSE gives insight into the short-term performance of a correlation. Low values for all statistic error measures are desired [25]. Earlier studies suggest that percentage errors between $-10 \%$ and $10 \%$ are acceptable [26].
Statistical analysis reported in Table 4 was calculated using the below;

Table 4: Error analysis

\begin{tabular}{lcc}
\hline & H-S & A-P \\
\hline RMSE $(M) / \mathrm{m}^{2} /$ day) & 2.14 & 2.34 \\
MPE (\%) & 3.85 & 6.15 \\
MAPE (\%) & 10.62 & 10.43 \\
MBE $\left(M J / \mathrm{m}^{2} /\right.$ day) & 0.74 & 1.01 \\
MABE $(M) / \mathrm{m}^{2} /$ day) & 1.65 & 1.65 \\
\hline
\end{tabular}




\section{Mean bias error (MBE) and mean absolute bias error (MABE)}

$$
\begin{gathered}
M B E=\frac{1}{n} \sum_{i=1}^{n}\left(H_{c}-H_{m}\right) \\
M A B E=\frac{1}{n} \sum_{i=1}^{n}\left(\left|H_{c}-H_{m}\right|\right)
\end{gathered}
$$

\section{Mean percentage error (MPE) and mean absolute percentage error (MAPE)}

$$
\begin{gathered}
M P E=\frac{1}{n} \sum_{i=1}^{n}\left(\frac{H_{c}-H_{m}}{H_{m}}\right) \times 100 \% \\
M A P E=\frac{1}{n} \sum_{i=1}^{n}\left|\left(\frac{H_{c}-H_{m}}{H_{m}}\right)\right| \times 100 \%
\end{gathered}
$$

\section{Root mean square errors (RMSE)}

$$
R M S E=\sqrt{\frac{\sum_{i=1}^{n}\left(H_{c}-H_{m}\right)^{2}}{n}}
$$

where $H_{c}$ and $H_{m}$ are the calculated and measured values of GSR, respectively.

Positive errors indicate that the models under study have overestimated values of GSR for the given period. The MPE falls within the prescribed interval $(-10 \% ; 10 \%)$, however the MAPE is slightly over the $10 \%$ interval (Table 4). This is a minor deviation in comparison to the daily sample size. Averaging and rounding of hourly, daily measurements when calculating monthly average values, would have contributed to the error being over the acceptable range. In this regard, the results are still acceptable. The RMSE, MBE and MABE values are moderate and can be lower to show a stronger correlation. The calculated values of $\mathrm{H}$ for Bisley conformed well to the shape of the data observed by the ARC, with the exception of a few outliers. This is represented in Figures 4 and 5. Maximum calculated values for $\mathrm{H}$ were observed during October - February (Figures 4 and 5) which are the spring and summer months in South Africa. Both the (H-S) and (A-P) models demonstrated the most deviation from the measured GSR values in these spring/summer months, which may indicate over estimation by the selected methods.

The over prediction may be a consequence of; the accuracy and competence of the equipment used, the effects of wind, or other temperature invasion factors such as pol-

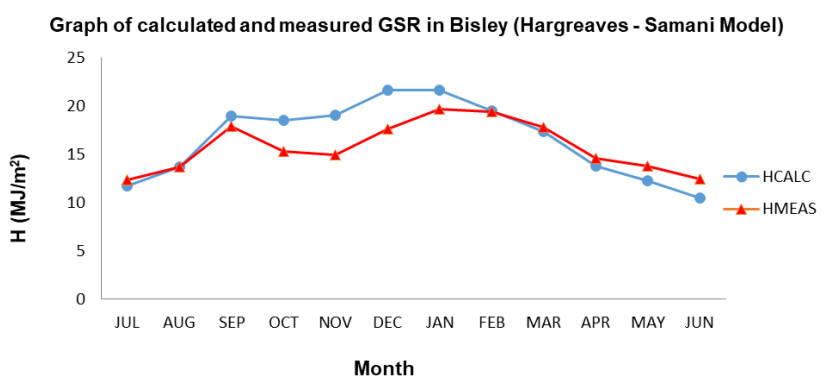

Figure 4: Graph comparing the measured and calculated values of $\mathrm{H}$ using the H-S Model

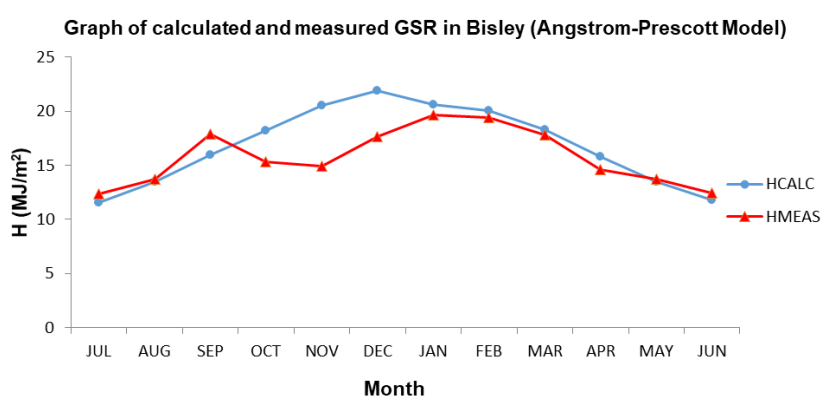

Figure 5: Illustration comparing the measured and calculated values of $\mathrm{H}$ using the A-P Model

lution. Observed values could be better validated by adjusting the temperature based model (H-S) to account for short wave radiation. The sunshine duration model may be modified by introducing a non-linear relationship between the GSR and sunshine duration ratio. For optimal prediction, this work suggests that a new model be devised to include both sunshine and temperature variables. This is a consequence of both models being able to sufficiently estimate the GSR in Bisley (based on the annual average errors), while each model performed differently when we consider each individual month. Other meteorological factors such as relative humidity, wind speed and air pressure can also be included for improved prediction. During the autumn, winter and parts of spring months, both models performed considerably well in estimating the amount of GSR. Overall, the distribution and monthly variation of the calculated values of GSR show great similarities when compared to the observed values.

The annual average GSR values obtained for Pietermaritzburg, show close similarities to the results presented by Maluta et al. [20], for the Limpopo Province in South Africa. In the study conducted by [20], stations which have an altitude close to that of Pietermaritzburg, had an annual average $H$ value in the range: [14.71-17.82] $\mathrm{MJ} / \mathrm{m}^{2}$, whilst $\mathrm{H}_{\text {calculated }}$ for Bisley is in the range: [16.5416.81] $\mathrm{MJ} / \mathrm{m}^{2}$. The main contributing difference in these locations is the site's latitude. 
The clearness index, being the ratio of GSR to extraterrestrial radiation provides information on the degree of transparency of the atmosphere. Using eq. (5), $K_{T}$ values were calculated and interpreted by the following work conducted in [6];

Table 5: Clearness index $\left(\mathrm{K}_{T}\right)$ results using each of the models

\begin{tabular}{cccc}
\hline Month & $\mathbf{K}_{T}$ (Hmeas) & $\mathbf{K}_{T}$ (H-S) & $\mathbf{K}_{T}(\mathbf{A}-\mathbf{P})$ \\
\hline Jul & 0.58 & 0.62 & 0.58 \\
Aug & 0.55 & 0.55 & 0.54 \\
Sep & 0.61 & 0.57 & 0.51 \\
Oct & 0.49 & 0.41 & 0.49 \\
Nov & 0.45 & 0.36 & 0.49 \\
Dec & 0.49 & 0.40 & 0.50 \\
Jan & 0.50 & 0.46 & 0.48 \\
Feb & 0.49 & 0.49 & 0.51 \\
Mar & 0.51 & 0.52 & 0.54 \\
Apr & 0.50 & 0.53 & 0.58 \\
May & 0.57 & 0.64 & 0.63 \\
Jun & 0.56 & 0.66 & 0.62 \\
Average & $\mathbf{0 . 5 3}$ & $\mathbf{0 . 5 2 0}$ & $\mathbf{0 . 5 4}$ \\
\hline
\end{tabular}

Table 6: Classification of day by clearness index, $\mathrm{K}_{T}$

\begin{tabular}{cc}
\hline Day Type & $\boldsymbol{K}_{T}$ \\
\hline Clear & $0.7 \leq \boldsymbol{K}_{T}<0.9$ \\
Partially Cloudy & $0.3 \leq \boldsymbol{K}_{T}<0.7$ \\
Cloudy & $0.0 \leq \boldsymbol{K}_{T}<0.3$ \\
\hline
\end{tabular}

The calculated values of clearness index for each model as shown in our results suggest that Pietermaritzburg experiences a high number of partially cloudy days, with not many days being classified as cloudy according to Table 5. The discrepancies experienced in the calculated $\mathrm{H}$ values may be a result of the influence of cloudiness on the air temperature and sunshine duration data. On average, the monthly data gives a clearness index which falls into the partially cloudy category for both prediction models as well as the measured data in question (Table 5).

In this study we have used the prescribed A-P coefficients of $a=0.25$ and $b=0.5$. The Angstrom coefficients vary with each geographical location depending on the amount of relative sunshine received. Other factors such as the geographical locations of the site and atmospheric effects may also introduce deviations in the clearness in- dex. For a more consistent set of Angstrom coefficients, this study should be extended to analyze data over a longer period of time for the chosen location.

The results obtained in this study indicate that the city of Pietermaritzburg receives sufficient GSR for the use of solar powered technologies such as solar panels, solar heating and cooling technologies for industrial, commercial and residential areas. Prediction models may be used to identify which areas are optimal for the harnessing of GSR. Accurate GSR predictions for this city will also enable a better understanding of the climate experienced and its effects. Clear to partially cloudy days are experienced throughout the year, including during the winter months, making GSR easy to acquire. The H-S and A-P models are suitable for the calculation of GSR, however the accuracy of results during the summer season can be improved. Comprehensive models including both meteorological variables can be introduced to account for this.

Evaluation of the A-P coefficients ( $a$ and $b$ ) as well as the H-S $\left(\mathrm{K}_{r}\right)$ coefficient can be conducted via the study of historic meteorological data for enhanced prediction models. These coefficients give insight into the transmissivity and transparency of the atmosphere. Prediction of the type of day and clearness index can also be made, provided the Angstrom coefficients are well-established. Though solar radiation data in the city of Pietermaritzburg is not readily available, the amount of GSR incident in this city can be sufficiently estimated using the Hargreaves-Samani and Angstrom-Prescott models. This study has shown the suitability of this interior region to contribute to the decrease in demand of grid energy by making use of the incident GSR in Pietermaritzburg. Furthermore, the forecasting method described above can be easily implemented for GSR prediction within any location of the world where air temperature and sunshine duration are measurable quantities.

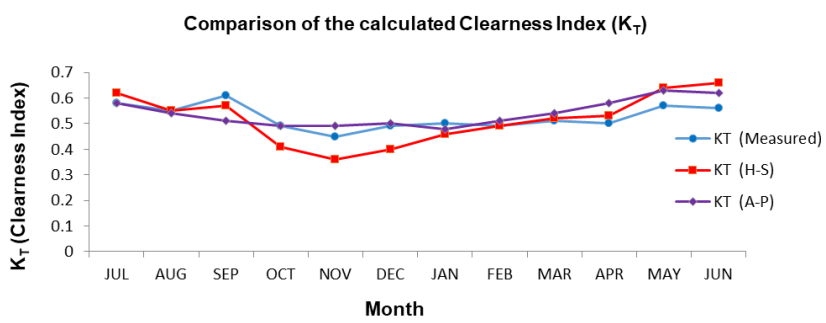

Figure 6: Graph comparing calculated and measured values of $\mathrm{K}_{T}$ 


\section{Conclusions}

The use of the H-S and A-P equations prove to be adequate methods of estimating the amount of GSR in locations where solar radiation data is not readily available. Our results show that these models have compared considerably well to the measured values of GSR for one suburb in the city of Pietermaritzburg. However, the accuracy of this model can be improved by modifying the equation to account for; more than one meteorological parameter (air temperature, sunshine duration, and relative humidity), shorter forecasting horizons and the inclusion of short wave radiation [23]. A second and third order prediction model may also be identified which could verify an increase in efficacy.

The results herein, show the degree of simplicity such models have, based on the use of one weather parameter alone. The H-S equation is viable for use in any geographical location since its dependency is mainly on the location and air temperature of a given site. While the A-P model performs considerably well without having an established, reliable set of Angstrom-Prescott coefficients. For better understanding and realization of a reliable set of A-P coefficients in Pietermaritzburg, it is suggested that we analyze the data for this city over a longer period $( \pm 10$ calendar years prior to current data). However, the results which we have obtained in just one calendar year show close proximity to the actual measured GSR values using the prescribed A-P coefficients for locations where this information is unknown.

KwaZulu-Natal is said to be unsuitable for the construction of large scale solar power plantations, primarily due to the low amount of Direct Normal Irradiation (DNI) incident in this province as opposed to the other eight provinces in South Africa [27]. Despite this, our province still receives ample sunshine duration and GSR for the utilization of solar technologies such as photovoltaic cells (both in Industry and for household consumption). With the implementation of accurate and efficient GSR prediction models, we will be able to identify which regions of Pietermaritzburg are suitable for optimal capture of solar radiation.

Acknowledgement: The authors would like to acknowledge the assistance of Mr. Richard Kunz of the University of KwaZulu-Natal Research center in Ukulinga, Bisley; The ARC (Cedara) who provided data to the Ukulinga Research Farm. The financial assistance of the National Research Foundation (DAAD-NRF) towards this research is hereby acknowledged. Opinions expressed and conclusions ar- rived at, are those of the author and are not necessarily to be attributed to the DAAD-NRF.

\section{References}

[1] Govinda R.T., Lado K., Patrick A. N., A review of solar energy, markets, economics and policies (Policy research working paper), The world bank, development and research group, environment and energy team, October 2011, http://econ. worldbank.org

[2] Eskom web page, http://www.eskom.co.za/AboutElectricity/ ElectricityTechnologies/Pages/Coal_Power.aspx

[3] Renewable Energy, Department: Energy, Republic of South Africa, http://www.energy.co.za/files/esources/renewables/r_ solar.html

[4] Qiang Fu., Radiation (Solar), 2003, University of Washington, Seattle, WA, USA, Elsevier Ltd.

[5] Sayigh A.A.M., Solar radiation availability prediction from climatological data, 1977, Academic Press, New York, 61.

[6] Viorel B., Modeling solar radiation at the earth's surface: Recent advances, Springer, 2008.

[7] Boeker E., Van Grondelle R., Environmental physics: Sustainable energy and climate change, 2011, 3rd Edition, John Wiley and Sons Ltd.

[8] Kennewell J., McDonald A., IPS-Satellite communications and space weather, The Australian Space Weather Agency, 2008, http://www.ips.gov.au/Educational/1/3/2

[9] Almorox J., Hontoria C., Benito M., Models for obtaining daily global solar radiation with measured air temperature data in Madrid (Spain), Applied Energy, 88, 2011, 1703-1709.

[10] Tijjani B.I., Comparison between first and second order Angstrom type models for sunshine hours in Katsina Nigeria, Bayero, J. Pure Appl. Sci., 4(2), 24-27.

[11] Rahimikoob A., Estimating global solar radiation using ANN and air temperature data in semi-arid environment (Iran), Renewable Energy, 2010, 35, 2131-2135.

[12] Al Riza D.F., Gilani S.I., Aris M.S., Hourly solar radiation estimation using ambient temperature and relative humidity data, Int. J. Envir. Sci. Develop., 2011, 2(3), June.

[13] Gadiwala M.S. Usman A., Akhtar M., Jamil K., Empirical models for the estimation of global solar radiation with sunshine hours on horizontal surface in various cities of Pakistan, Pakistan J. Meteorol., 2013, 9(18), Jan.

[14] Angstrom A., Solar and atmospheric radiation. International commission for solar research on Actinometric Investigations of solar and atmospheric radiation, J. Royal Meteorol. Soc., 1923, 121-126.

[15] Srivasta R.C., Pandey H., Estimating Angstrom-Prescott coefficients for India and developing a correlation between sunshine hours and global solar radiation for India, ISRN Renewable Energy, 2013, Hindawi Publishing, http://dx.doi.org/10. $1155 / 2013 / 403742$

[16] Ituen Eno E., Esen Nisken U., Nwokolo Samuel C., Uto Ema G., Prediction of Global solar radiation using relative humidity, maximum temperature and sunshine hours in Uyo in the Niger delta Region, Nigeria, Advances in Applied Science Research, 2012, 3(4), 1923-1937. 
[17] Samani Z., Estimating solar radiation and evapotranspiration using minimum climatological data, J. Irrig. Drain. Eng., 2000, 265-267.

[18] Allen R.G., Self-calibrating method for estimating global solar radiation from air temperature, J. Hydrol. Eng., 1991, 2, 56-57.

[19] Hargreaves G.H., Samani Z.A., Estimating potential evapotranspiration, J. Irrig. Drain. Eng., ASCE, 108(IR3), 1982, 223-230.

[20] Maluta E.N., Maludzi T.S., Sankaran V., Estimation of the global solar radiation on the horizontal surface from temperature data for the Vhembe district in the Limpopo province of South Africa, International journal of green energy, 2013, 11(5), 454-464.

[21] Salima G., Chavula G.M.S., Determining Angstrom coefficients for estimating solar radiation in Malawi, Int. J. Geosciences, 2012, (3), 391-397.

[22] Teke A., Yildirim H.B., Estimating the monthly global solar radiation for Eastern Mediterranean Region, Energy Conv. Management 2014, 87, 628-635.
[23] Allen R.G., Pereira S.L., Raes D., Smith M., Crop evapotranspiration (Guidelines for computing crop water requirements), FAO Irrigation and Drainage, 1977, 56.

[24] Almorox J., Bocco M., Wellington E., Estimation of daily global solar radiation from measured temperatures at Cañada de Luque, Córdoba, Argentina, Renew. Ener., 2013, 60, 382-387.

[25] Marwal V.K., Punia R.C., Sengar N., Mahawar S., Dashora P., A comparative study of correlation functions for estimation of monthly mean daily global solar radiation for Jaipur, Rajasthan (India), Indian J. Sci. Techn., 2012, 5(5), 2729-2732.

[26] Robaa S.M., Evaluation of sunshine duration from cloud data in Egypt, Energy, 2008, 33(5), 789-795.

[27] Fluri T.P., The potential of concentrating solar power in South Africa, Energy Policy 2009, 37, 5075-5080. 